\title{
Effects of work-related factors on the breastfeeding behavior of working mothers in a Taiwanese semiconductor manufacturer: a cross-sectional survey
} Yi Chun Chen ${ }^{1}$, Ya-Chi Wu ${ }^{2}$ and Wei-Chu Chie*3

\author{
Address: ${ }^{1}$ School of Nutrition and Health Sciences, Taipei Medical University, 250 Wu-Hsing Street, Taipei 110, Taiwan, ${ }^{2}$ Division of Clinical \\ Sciences, Center for Drug Evaluation, 1F, No15-1, Sec. 1, Hangjou S. Rd., Taipei 100, Taiwan and ${ }^{3}$ Department of Public Health and Institute of \\ Preventive Medicine, College of Public Health, National Taiwan University, room 520, No.17 Xu-Zhou Road, Taipei, 100, Taiwan \\ Email: Yi Chun Chen - yichun@tmu.edu.tw; Ya-Chi Wu - ycwu@cde.org.tw; Wei-Chu Chie* - weichu@ntu.edu.tw \\ * Corresponding author
}

Published: 2I June 2006

BMC Public Health 2006, 6:160 doi:10.1 186/147/-2458-6-160

This article is available from: http://www.biomedcentral.com/I47I-2458/6/160

(C) 2006 Chen et al; licensee BioMed Central Ltd.

This is an Open Access article distributed under the terms of the Creative Commons Attribution License (http://creativecommons.org/licenses/by/2.0), which permits unrestricted use, distribution, and reproduction in any medium, provided the original work is properly cited.
Received: 18 October 2005

Accepted: 21 June 2006

\begin{abstract}
Background: In recent years, the creation of supportive environments for encouraging mothers to breastfeed their children has emerged as a key health issue for women and children. The provision of lactation rooms and breast pumping breaks have helped mothers to continue breastfeeding after returning to work, but their effectiveness is uncertain. The aim of this study was to assess the effects of worksite breastfeeding-friendly policies and work-related factors on the behaviour of working mothers.
\end{abstract}

Methods: This study was conducted at a large Taiwanese semiconductor manufacturer in AugustSeptember 2003. Questionnaires were used to collect data on female employees' breastfeeding behaviour, child rearing and work status when raising their most recently born child. A total of 998 valid questionnaires were collected, giving a response rate of $75.3 \%$.

Results: The results showed that $66.9 \%$ of survey respondents breastfed initially during their maternity leave, which averaged 56 days. Despite the provision of lactation rooms and breast pumping breaks, only $10.6 \%$ mothers continued to breastfeed after returning to work, primarily office workers and those who were aware of their company's breastfeeding-friendly policies.

Conclusion: In conclusion, breastfeeding-friendly policies can significantly affect breastfeeding behaviour. However, an unfavourable working environment, especially for fab workers, can make it difficult to implement breastfeeding measures. With health professionals emphasizing that the importance of breastfeeding for infant health, and as only females can perform lactation, it is vital that women's work "productive role" and family "reproductive role" be respected and accommodated by society.

\section{Background}

In recent years, the creation of supportive environments for encouraging mothers to breastfeed their children has emerged as a key health issue for women and children.
While the number of new mothers in the workplace increases, an early return to work and inconvenient workplace conditions discourage women from breastfeeding or cause them to discontinue breastfeeding early [1-3]. 
The World Health Organization (WHO) recommends exclusive breastfeeding for the first six months of life [4]. The length of maternity leave is positively associated with the duration of breastfeeding $[5,6]$. The International Labour Organization (ILO) recommends a period of maternity leave of not less than 14 weeks [7]. However, the typical maternity leave in many Asian and Middle Eastern countries falls below these levels, only offering less than 12 weeks paid leave [8]. In Taiwan, most companies provide only eight weeks of maternity leave. A national survey in 2005 showed that the rate of exclusive breastfeeding in Taiwan at one month postpartum was only $22.3 \%$, and dropped to $16.7 \%$ at three months [9]. To bring Taiwan in line with WHO guidelines, effective worksite strategies needed to be implemented to encourage new mothers to breastfeed in the workplace.

The provision of lactation rooms and breast pumping breaks have helped mothers to continue breastfeeding after returning to work, but their effectiveness is uncertain. This study examines breastfeeding policies in a large Taiwanese semiconductor manufacturer. The semiconductor industry is key growth river of Taiwan's economy, and also plays a significant role in the economies of many other developing and newly industrialized countries. Thus, the breastfeeding needs of female workers in Taiwan's semiconductor companies are very important and similar to such countries. The study also examines work-related factors that affect women's breastfeeding behavior.

The purpose of the study is to conduct a survey of new mothers in the workplace to explore the correlation between breastfeeding and work barriers to achieving WHO recommendations.

\section{Methods}

\section{Research setting and subjects}

The research setting is Company $\mathrm{T}$, a large semiconductor manufacturer with 10,000 employees in Hsinchu Science Park in northern Taiwan, which is one of the world's most significant areas for semiconductor manufacturing, similar in importance to Silicon Valley. This company was selected because it was the first semiconductor manufacturer to provide lactation rooms and breast pumping breaks for working mothers, which was an uncommon practice at the time the survey was conducted. Secondly, about $50 \%$ of the company's employees are women, most of whom are of childbearing age. Thirdly, the female employees are office workers or fab workers or, so the influence of different working conditions on breastfeeding behavior could be observed.

Office workers had superior educational levels and higher compensation levels compared with the fab (fabricating) workers, and they worked about eight hours a day from
08:30 to 18:00. Their positions encompassed specific job responsibilities, and so their bonuses were largely tied to individual performances. By comparison, fab workers worked 12-hour shifts, from 07:00 to 19:00, or from 19:00 to 07:00. Their jobs were inconvenient and inflexible, as they have to remove and put back on their clean room suits when leaving and returning to their workstation, and a substitute had to take their place during their absence. Performance bonuses at most Taiwanese manufacturers are based on both group productivity and individual performance criteria. It is the group leader's responsibility to promote higher productivity as well as evaluate individual performances. If productivity is very high, a worker's annual bonus can usually exceed their base salary. Therefore, most workers will do their best to maximize productivity.

\section{Data collection and variable definitions}

This study was conducted between April and September 2003. Questionnaires were used to collect data on female employees' breastfeeding behaviour, child rearing and work status when raising their most recently born child (See Additional file 1). In developing the questionnaire, in-depth interviews were conducted with 25 female workers at Company T. Seven public health professionals also reviewed and revised the questionnaire. The preliminary questionnaire was further revised after it was used in a pilot study at another semiconductor manufacturer. The final questionnaire was then distributed in August and September 2003 to 1,326 female employees, whom had taken maternity leave between January 1999 and April 2003 as recorded by the manufacturer's human resource department. The company's occupational and environmental health nurses helped distribute and collect the questionnaires. To help clarify questionable answers, the questionnaire was not anonymous, but all personal information and answers were kept confidential by the researchers. Written consent was not required in questionnaire survey. Participation in this study is entirely voluntary. We described the aims of this study and invited the subjects to participate in this study, and oral consent was obtained from the participants. This study was reviewed and approved by the ethics committee of the College of Public Health, National Taiwan University.

The study used two dependent variables: breastfeeding initiation (whether or not the mother had ever breastfed the most recently born child) and continuation of breastfeeding after returning to work (yes or no). A mother initiated breastfeeding if she had ever breastfed her child. Mothers were defined as breastfeeding only during maternity leave (initiation and no continuation) if they completely stopped breastfeeding before, or within two weeks after returning to work. Mothers were defined as continu- 
ing breastfeeding if they continued for at least two weeks after returning to work.

Several employment characteristics were analyzed as independent variables, including worksite (fab/office), according to human resource department records), shift work ("Did you do shift work after you returned to work?" yes/ no), flextime ("Did you need any substitute when you left your position during working hours? " yes/no), child's age ( $<1$ year, $1-3$ years or $>3$ years) and length of employment ( $\leq 6$ years, $7-9$ years or $\geq 10$ years). Other independent variables were an employee's knowledge of breastfeeding policies in the workplace, including awareness of lactation rooms ("Did you know about the lactation room in your company?" yes/no) and awareness of breast pumping breaks. ("Did you know about pumping breaks? " yes/no).

\section{Statistical analysis}

The effects of employment characteristics and manufacturer policies on breastfeeding behavior were estimated using chi-square tests and logistic regression. Preliminary associations between categorical variables were verified through chi-square tests on contingency tables. Logistic regression was used to analyze breastfeeding behavior with respect to the following variables: age, education, worksite, shift work, years of employment and policy awareness. Variables were culled after an evaluation of their collinearity. If two or more variables were highly correlated, separate models were run for each of the collinear variables, and the model with the strongest relation to the breastfeeding measures was selected. Statistical analyses were conducted using SAS Version 8.2.

\section{Results \\ Demographic and social characteristics of respondents}

A total of 998 valid questionnaires were collected, giving a response rate of $75.3 \%$. As shown in Table 1, the mean age of the mothers was 29.8 years, and the mean maternity leave was 56.8 days. About half of the women had either a high school degree $(51.6 \%)$ or a college degree (48.4\%). $43.3 \%$ were first-time mothers and $50.9 \%$ of newly borns were male. Most worked in the semiconductor fab $(82.1 \%)$, were shift workers $(77.2 \%)$, and their work time was inflexible (70.6\%). The breastfeeding initiation rate was $66.9 \%$, but $62.5 \%$ of breastfeeding mothers only breastfed less than one month.

\section{Breastfeeding status}

Breastfeeding behavior was grouped according to sociodemographic and working characteristics, as shown in Table $2.56 .3 \%$ only breastfed during maternity leave, and $33.1 \%$ never breastfed. Despite the provision of lactation rooms and breast pumping breaks, only $10.6 \%$ continued to breastfeed after returning to work. All independent var- iables were significantly correlated to breastfeeding behavior $(\mathrm{p}<0.001)$. Older age, lower education, fab work, shift work, inflexible schedule, and not knowing about worksite breastfeeding policies were all associated with the discouragement breastfeeding initiation. Of those who did not know about the lactation rooms, $47.2 \%$ never breastfed their last child. A child's age and years of employment were negatively correlated to breastfeeding initiation. Almost half of women whose children were more than three year's old, and $49.7 \%$ of those who had worked for the company for ten or more years, did not initiate breastfeeding.

Older age, higher education, less than one-year old child, office work, non-shift work, flexible schedule and knowing about worksite breastfeeding policies were all associated with the increased likelihood of a mother continuing to breastfeed after returning to work. $29.2 \%$ of office workers continued to breastfeed. Of those who knew about lactation rooms, $13.5 \%$ continued to breastfeed, whereas $20.1 \%$ of those who knew about breast pumping breaks continued to breastfeed. Mothers who were employed for ten or more years had the lowest continuation rate.

\section{Multivariate logistic regression analysis}

Table 3 shows the results of the logistic regression analysis. Shift work was excluded from the models because it was highly correlated with the worksite location $(\gamma=$ 0.83 ). Flextime was excluded because it had little or no effect on the models. Age, education, worksite, years of employment and awareness of lactation room were significantly correlated with breastfeeding initiation. Only the child's age, worksite location, awareness of lactation rooms, and awareness about breast pumping breaks were significantly correlated with continued breastfeeding. The odds ratio (OR) of continuing breastfeeding was 2.53 (95\% CI, 1.55-4.14) for child aged $<1$ year old and 1.64 (95\%CI, 1.10-2.42) for child aged between 1 and 3 years. The OR of continuing breastfeeding was 4.32 (95\% CI, 2.30-8.11) for office workers, 2.71 (95\%CI, 1.19-6.15) for women who knew about the lactation rooms and 2.68 (95\%CI, 1.57-4.58) for women who knew about breast pumping breaks.

\section{Awareness of policy and worksite}

Table 4 shows the different effects of breastfeeding policy awareness between office and fab workers. Workers who knew about the lactation rooms were significantly more likely to initiate breastfeeding. The OR of initiating breastfeeding was 7.88 (95\% CI, 2.36-26.32) for fab workers and 2.83 (95\% CI, 0.99-8.06) for office workers. Policy awareness had a stronger effect on continuing breastfeeding for office workers than for fab workers. For fab workers, only awareness of breast pumping breaks was 
Table I: Characteristics of study subjects

\begin{tabular}{|c|c|}
\hline & No. (\%) \\
\hline \multicolumn{2}{|l|}{ Age (year) } \\
\hline $20-24$ & $066(06.6)$ \\
\hline $25-29$ & $419(42.0)$ \\
\hline $30-34$ & $406(40.7)$ \\
\hline$\geq 35$ & $107(10.7)$ \\
\hline Mean \pm SD & $29.8 \pm 3.7$ \\
\hline \multicolumn{2}{|c|}{ Maternity leave (day) } \\
\hline$<56$ days & $1 \mid 4(|| .5)$ \\
\hline $56-60$ days & $835(84.0)$ \\
\hline$>60$ days & $045(04.5)$ \\
\hline Mean \pm SD & $56.8 \pm 10.7$ \\
\hline \multicolumn{2}{|c|}{ Breastfeeding initiation* } \\
\hline Yes & 587 (66.9) \\
\hline No & $291(33.1)$ \\
\hline \multicolumn{2}{|c|}{ Breastfeeding duration } \\
\hline$<$ I month & $367(62.5)$ \\
\hline $\mathrm{I}-2$ month & $127(21.6)$ \\
\hline$>2$ month & $093(15.8)$ \\
\hline \multicolumn{2}{|l|}{ Education* } \\
\hline$\leq$ High school & $512(51.6)$ \\
\hline$\geq$ College & $480(48.4)$ \\
\hline \multicolumn{2}{|c|}{ Number of children* } \\
\hline 1 & $432(43.3)$ \\
\hline 2 & $44 I(44.3)$ \\
\hline$\geq 3$ & $124(12.4)$ \\
\hline \multicolumn{2}{|l|}{ Gender of child* } \\
\hline Boy & $504(50.9)$ \\
\hline Girl & $487(49.1)$ \\
\hline \multicolumn{2}{|l|}{ Worksite } \\
\hline Fab & $819(82.1)$ \\
\hline Office & $179(17.9)$ \\
\hline \multicolumn{2}{|l|}{ Shift Work } \\
\hline No & $228(22.8)$ \\
\hline Yes & 770 (77.2) \\
\hline \multicolumn{2}{|l|}{ Flextime } \\
\hline Yes & $282(29.4)$ \\
\hline No & $676(70.6)$ \\
\hline
\end{tabular}

* missing values excluded.

significantly related to continuing breastfeeding ( $\mathrm{OR}=$ $2.15,95 \% \mathrm{CI}, 1.09-4.26)$. For office workers, the OR for continuing breastfeeding was significantly higher for those who knew about the lactation rooms $(\mathrm{OR}=6.53$, 95\% CI, 1.33-32.13) and those who knew about the breast pumping breaks (OR $=4.91,95 \% \mathrm{CI}, 1.79-13.46)$. For those women who knew about both the lactation rooms and breast pumping breaks, there was a higher probability that office workers would continue breastfeeding $(\mathrm{OR}=8.65,95 \% \mathrm{CI}, 2.48-30.18)$.

\section{Discussion}

\section{Breastfeeding status}

In this study, the average breastfeeding rate was $66.9 \%$. It was much higher than the national average of $22.3 \%$ at one month postpartum [9]. However, the rate of breastfeeding after returning to work was only $10.6 \%$, much lower than the national average of $16.7 \%$ at three months postpartum [9]. Furthermore, the rates differed among groups. Younger mothers were more likely than older women to breastfeed, but most of them only breastfed during maternity leave. Most of the younger mothers worked in the fab plant and so may found it difficult to use the breast pumping breaks and lactation rooms, implying that an inconvenient working environment is an important barrier to breastfeeding among working mothers. Mothers with children less than three years old were more likely to continue breastfeeding than those with older children. This may not only because the memory 
Table 2: Breastfeeding behavior of respondents by socio-demographic and working characteristics

\begin{tabular}{|c|c|c|c|c|}
\hline & \multirow[t]{2}{*}{ Never breastfed } & \multicolumn{2}{|c|}{ Ever breastfed } & \multirow{3}{*}{ Chi-square $\mathrm{P}$} \\
\hline & & $\begin{array}{c}\text { Only during maternity } \\
\text { leave }\end{array}$ & $\begin{array}{c}\text { Continued after returning } \\
\text { to work }\end{array}$ & \\
\hline & n (\%) & n (\%) & n (\%) & \\
\hline Total* & 291 (33.1) & $494(56.3)$ & $93(10.6)$ & \\
\hline \multicolumn{5}{|l|}{ Age, years* } \\
\hline$<30$ & $123(28.5)$ & $275(63.6)$ & $34(07.9)$ & $<0.001$ \\
\hline$\geq 30$ & $168(37.7)$ & $219(49.1)$ & $59(13.2)$ & \\
\hline \multicolumn{5}{|l|}{ Education* } \\
\hline$\geq$ College & $99(23.7)$ & $25 I(60.2)$ & $67(16.1)$ & $<0.001$ \\
\hline$\leq$ High school & $188(4 \mid .2)$ & $242(53.1)$ & $26(05.7)$ & \\
\hline \multicolumn{5}{|l|}{ Children's age } \\
\hline$<1 \mathrm{yr}$ & $45(2 l .1)$ & $133(62.5)$ & $35(16.4)$ & $<0.001$ \\
\hline $\mathrm{I}-3 \mathrm{yr}$ & $164(32.6)$ & 291 (57.7) & 49 (09.7) & \\
\hline$>3 \mathrm{yr}$ & $82(50.9)$ & $70(43.5)$ & $9(05.6)$ & \\
\hline \multicolumn{5}{|l|}{ Worksite } \\
\hline Office & $29(18.8)$ & $80(52.0)$ & $45(29.2)$ & $<0.001$ \\
\hline $\mathrm{Fab}$ & $262(36.2)$ & $414(57.2)$ & $48(06.6)$ & \\
\hline \multicolumn{5}{|l|}{ Shift work } \\
\hline No & $46(24.1)$ & $98(51.3)$ & $47(24.6)$ & $<0.001$ \\
\hline Yes & $245(35.7)$ & $396(57.6)$ & $46(06.7)$ & \\
\hline \multicolumn{5}{|l|}{ Flextime $*$} \\
\hline Yes & $69(28.6)$ & $126(52.3)$ & $46(19.1)$ & $<0.001$ \\
\hline No & $210(34.8)$ & $350(58.1)$ & $43(07.1)$ & \\
\hline \multicolumn{5}{|c|}{ Employment, years * } \\
\hline$\leq 6$ & $130(28.4)$ & $276(60.4)$ & $51(11.2)$ & $<0.001$ \\
\hline $7-9$ & $81(31.2)$ & $150(57.7)$ & $29(11.1)$ & \\
\hline$\geq 10$ & $80(49.7)$ & $68(42.2)$ & $13(8.1)$ & \\
\hline \multicolumn{5}{|c|}{$\begin{array}{l}\text { Awareness of lactation } \\
\text { rooms * }\end{array}$} \\
\hline Yes & $173(27.5)$ & $371(59.0)$ & $85(13.5)$ & $<0.001$ \\
\hline No & $117(47.2)$ & $123(49.6)$ & $8(03.2)$ & \\
\hline \multicolumn{5}{|c|}{$\begin{array}{l}\text { Awareness of breast } \\
\text { pumping breaks } *\end{array}$} \\
\hline Yes & $49(30.8)$ & $78(49.1)$ & $32(20.1)$ & $<0.001$ \\
\hline No & $238(33.5)$ & $4 \mid 2(58.0)$ & $60(08.5)$ & \\
\hline
\end{tabular}

* missing values excluded.

recall effect but also the effect of pro-breastfeeding governmental policy and social environment in recent years.

\section{Importance of policy}

The study found that awareness of breastfeeding-friendly measures in the workplace can significantly increase continued breastfeeding rate after returning to work. But as breastfeeding after returning to work is still a new practice in Taiwan, and the target company has made considerable efforts to establish and promote this policy, the possibility of reverse causality is not very high. It is important to encourage industries to provide breastfeeding support services, such as providing breast pumping breaks or lactation rooms. Previous research has shown that work is one of the biggest obstacles to breastfeeding [10-12]. Though breastfeeding and employment are not mutually exclusive[13], longer periods of maternity leave may be a good solution to promote breastfeeding $[14,15]$. However, it would be a lengthy process to change the law and could impose additional economic costs on the government or companies. A more achievable goal is the encouragement of more breastfeeding-friendly workplace environments and the promotion of breastfeeding policies.

\section{Effect of worksite}

This study found that breastfeeding-friendly policies can significantly affect whether office (white collar) workers start or continue to breastfeed after returning to work. Breastfeeding policies also influence the breastfeeding behavior of fab (blue collar) workers, but the effect is not as significant. The low percentage of those starting or continuing to breastfeed was partly because of an inconvenient working environment. Even when the manufacturer 
Table 3: Factors related to breastfeeding by multivariate logistic regression

\begin{tabular}{|c|c|c|c|c|c|c|}
\hline & \multicolumn{3}{|c|}{ Ever breastfed* } & \multicolumn{3}{|c|}{$\begin{array}{c}\text { Continued breastfeeding after returning to } \\
\text { work } \dagger\end{array}$} \\
\hline & OR $\ddagger$ & $(95 \% \mathrm{Cl})$ & $P$ value & OR $\ddagger$ & $(95 \% \mathrm{Cl})$ & $P$ value \\
\hline \multicolumn{7}{|l|}{ Age, years } \\
\hline$<30 / \geq 30$ & 1.37 & $(0.99-1.89)$ & 0.057 & 0.69 & $(0.40-1.23)$ & 0.211 \\
\hline \multicolumn{7}{|l|}{ Education } \\
\hline$>$ College/ $\leq$ College & 1.59 & $(1.12-2.17)$ & 0.008 & 1.03 & $(0.57-1.87)$ & 0.926 \\
\hline \multicolumn{7}{|l|}{ Children's age } \\
\hline$<1 \mathrm{yr} />3 \mathrm{yr}$ & 1.34 & $(0.54-3.3 \mathrm{I})$ & 0.529 & 2.53 & $(1.55-4.14)$ & $<0.001$ \\
\hline $1-3 \mathrm{yr} />3 \mathrm{yr}$ & 0.85 & $(0.36-1.99)$ & 0.701 & 1.64 & $(1.10-2.42)$ & 0.014 \\
\hline \multicolumn{7}{|l|}{ Worksite } \\
\hline Office/Fab & 2.33 & $(1.40-3.87)$ & 0.001 & 4.32 & $(2.30-8.11)$ & $<0.001$ \\
\hline \multicolumn{7}{|l|}{ Employment, years } \\
\hline$\leq 6 / \geq 10$ & 1.77 & $(1.17-2.67)$ & 0.007 & 1.14 & $(0.53-2.43)$ & 0.745 \\
\hline $7-9 / \geq 10$ & 1.91 & $(1.25-2.94)$ & 0.003 & 0.83 & $(0.42-2.02)$ & 0.826 \\
\hline \multicolumn{7}{|c|}{ Awareness of lactation rooms } \\
\hline Yes/No & 1.60 & $(1.14-2.24)$ & 0.006 & 2.71 & $(1.19-6.15)$ & 0.017 \\
\hline \multicolumn{7}{|c|}{ Awareness of breast pumping breaks } \\
\hline Yes/No & 0.87 & $(0.59-1.28)$ & 0.474 & 2.68 & $(1.57-4.58)$ & $<0.001$ \\
\hline
\end{tabular}

Note: $\mathrm{OR}=$ odds ratio; $\mathrm{Cl}=$ confidence interval.

*Women who never breastfed as reference group.

† Women who only breastfed during maternity leave as reference group.

$\ddagger$ Adjusted for all other variables in the table.

provided a lactation room and allowed one hour for milk expression, fab workers found it difficult to make the most of these measures: fab workers needed time to take off and put on their clean room suit, and it could take 1015 minutes to travel between the very large cleaning room and the lactation room, leaving limited time for milk expression. This might help explain why the percentage of fab workers starting or continuing to breastfeed was low. Another possible reason is that women who breastfeed were more likely to find out about and paid attention to what benefits were available. Since the study was a crosssectional study, it was our research limitation to find out the causality.

Research has also found that blue-collar worker participation in worksite health promotion programs is lower than that for white-collar workers [16-18]. This does not necessarily mean that blue-collar workers are less concerned about health issues, but rather it may reflect their own difficult circumstances, such as the lack of a supervisor's social support. For blue-collar workers, supervisors function as gatekeepers who control a worker's access to health promotion activities. For instance, to keep production lines moving, supervisors may refuse to allow workers to attend programs on company time [19]. This study also found that the group leader and the manufacturer's performance bonus system may reduce a woman's willingness to start or continue breastfeeding in the workplace. If a group leader disagrees with breastfeeding but the mother continues to breast pump during work hours, it will affect her work performance and bonus. Even if a mother sacrifices her bonus, her performance can affect the group's overall performance and collective bonus, such that the resulting negative working atmosphere could force a mother to choose between breastfeeding and her

job.

\section{Worksite breastfeeding promotion}

This study found that breastfeeding policies and facilities had a smaller effect on breastfeeding of fab workers than office workers. It also revealed that breastfeeding is not valued in the workplace. These findings were particularly relevant for Asian countries where maternity leave is short and most women return to work in the immediate postpartum period to full-time jobs where they have little direct control over their work environment. One survey found that most employers would be willing to institute policies that facilitate breastfeeding or breast pumping in the workplace. However, these employers saw little value to their business of supporting breastfeeding. [20] Another survey found that, while employers knew about the benefits of breastfeeding for mothers and children, they did not place a high priority on providing breastfeeding support [21]. For worksite breastfeeding promotion programs to be effective, they must involve not only the mothers, but also the employers and fellow workers. 
Table 4: Effects of awareness of policy on breastfeeding behaviors

\begin{tabular}{|c|c|c|c|c|c|c|}
\hline & \multicolumn{3}{|c|}{ Ever breastfed* } & \multicolumn{3}{|c|}{ Continued breastfeeding after returning to work $\dagger$} \\
\hline & OR $\ddagger$ & $(95 \% \mathrm{Cl})$ & $P$ value & OR* & $(95 \% \mathrm{Cl})$ & $P$ value \\
\hline \multicolumn{7}{|l|}{ Stratified by worksite } \\
\hline Awareness of lactation room & \multicolumn{6}{|c|}{ Fabł } \\
\hline Yes/No & 7.88 & $(2.36-26.32)$ & 0.001 & 2.06 & $(0.78-5.40)$ & 0.143 \\
\hline \multicolumn{7}{|c|}{ Awareness of breast pumping breaks } \\
\hline Yes/No & 0.84 & $(0.56-1.26)$ & 0.399 & 2.15 & $(1.09-4.26)$ & 0.028 \\
\hline Awareness of lactation rooms & \multicolumn{6}{|c|}{ Office $\ddagger$} \\
\hline Yes/No & 2.83 & $(0.99-8.06)$ & 0.052 & 6.53 & $(1.33-32.13)$ & 0.021 \\
\hline \multicolumn{7}{|c|}{ Awareness of breast pumping breaks } \\
\hline Yes/No & 1.14 & $(0.33-3.95)$ & 0.833 & 4.91 & $(1.79-13.46)$ & 0.002 \\
\hline \multicolumn{7}{|c|}{ Selected by awareness of policy } \\
\hline Worksite & \multicolumn{6}{|c|}{ High awareness of policy $\ddagger \S$} \\
\hline Office/Fab & 2.38 & $(0.65-8.7 I)$ & 0.189 & 8.65 & $(2.48-30.18)$ & 0.001 \\
\hline
\end{tabular}

*Women who never breastfed as reference group.

† Women who only breastfed during maternity leave as reference group.

$\ddagger$ Adjusted for mother's age, education, employment and children's age.

$\S$ Only women who both knew about lactation rooms and breast pumping breaks in the model.

\section{Conclusion}

Some researchers opine that a mother's intention and breastfeeding knowledge are the key factors affecting breastfeeding behavior $[22,23]$. But intention or knowledge alone is not sufficient to overcome barriers to breastfeeding. We found that poor breastfeeding rates among blue-collar mothers in a company with breastfeedingfriendly policies was, at least in part, related to an inconvenient working environment. Galtry found that being blue collar or lower income generally implies lower skill requirements, less flexibility and even less protective working rights [24]. American Academy of Pediatrics Section on Breastfeeding indicated that exclusive breastfeeding for six months would lower the risk of morbidity and mortality of infants [25]. It is necessary to have more comprehensive breastfeeding-friendly measures in the workplace. The fab workers described in this study need more coordinated measures to support them in continuing to breastfeed after returning to work. Before criticizing women who discontinued breastfeeding, it is necessary to consider the environmental obstacles that mothers face and act to overcome them. Therefore, efforts at promoting breastfeeding need to deal with the mothers multiple enabling aspects, such as their socio-economic, cultural, and psychological conditions.

\section{Competing interests}

The author(s) declare that they have no competing interests.

\section{Authors' contributions}

Y. C. C. conducted the study, synthesized analyses and wrote the drafts of the article.
Y. C. W. undertook statistical analyses.

W. C. C. supervised the study and led the writing.

All authors helped to conceptualize ideas, interpret findings, and review drafts of the manuscript. All authors read and approved the final manuscript.

\section{Additional material}

\section{Additional File 1}

The file is a word file of the original questionnaire. Invitation and subject's information were not included.

Click here for file

[http://www.biomedcentral.com/content/supplementary/1471-

2458-6-160-S1.doc]

\section{Acknowledgements}

This study was support by a grant from National Science Council, Taipei, Taiwan (NSC 92-2320-B038-046). We gratefully acknowledge the assistance of all the occupational nurses in Wellness Section, Company $T$ in ensuring high response rates to the survey.

\section{References}

I. Kearney MH, Cronenwett L: Breastfeeding and employment. J Obstet Gynecol Neonatal Nurs 1991, 20(6):47 I-480.

2. Fein SB, Roe B: The effect of work status on initiation and duration of breast-feeding. American Journal of Public Health 1998, 88(7): 1042-1046.

3. Meek JY: Breastfeeding in the workplace. Pediatric Clinics of North America 200I, 48(2):46I-474.

4. WHO: The World health report: 2005: make every mother and child count. 2005.

5. Visness CM, Kennedy KI: Maternal employment and breastfeeding: findings from the 1988 National Maternal and Infant 
Health Survey. American Journal of Public Health 1997, 87(6):945-950.

6. Hammer LD, Bryson S, Agras WS: Development of feeding practices during the first 5 years of life. Archives of Pediatrics \& Adolescent Medicine 1999, 153(2):189-194.

7. Organization IL: Maternity Protection Convention 183.

8. The World Alliance for Breastfeeding Action: Status of Maternity Protection by Country. Breastfeeding, women and work .

9. Chien LY, Chu KH, Tai CJ, Lin CY: National prevalence of breastfeeding in Taiwan. J Hum Lact 2005, 2 I (3):338-344.

10. Lindberg $L$ : Trends in the relationship between breastfeeding and postpartum employment in the United States. Social Biology 1996, 43(3-4): 19|-202.

II. Lindberg LD: Women's decisions aboust breastfeeding and maternal employment. Journal of Marriage and the Family 1996, 58:239-25I.

12. Roe B, Whittington LA, Fein SB, Teisl MF: Is there competition between breast-feeding and maternal employment? Demography 1999, 36:157-171.

13. Yimyam S, Morrow M, Srisuphan W: Role conflict and rapid socio-economic change: breastfeeding among employed women in Thailand. Social Science \& Medicine 1999, 49(7):957-965.

14. Galtry J: Lactation and the labor market: breastfeeding, labor market changes, and public policy in the United States. Health Care for Women International 1997, I 8(5):467-480.

15. Galtry J: The impact on breastfeeding of labour market policy and practice in Ireland, Sweden, and the USA. Soc Sci Med 2003, 57(I): 167-177.

16. Glasgow RE, McCaul KD, Fisher KJ: Participation in worksite health promotion: a critique of the literature and recommendations for future practice. Health Education Quarterly 1993, 20(3):39|-408.

17. Sorensen G, Stoddard A, Ockene JK, Hunt MK, Youngstrom R: Worker participation in an integrated health promotion/ health protection program: results from the WellWorks project. Health Educ Q 1996, 23(2): 19|-203.

18. Morris WR, Conrad KM, Marcantonio RJ, Marks BA, Ribisl KM: Do blue-collar workers perceive the worksite health climate differently than white-collar workers? American Journal of Health Promotion 1999, 13(6):319-24, ii.

19. Sorensen G, Barbeau E, Hunt MK, Emmons K: Reducing social disparities in tobacco use: a social-contextual model for reducing tobacco use among blue-collar workers. Am J Public Health 2004, 94(2):230-239.

20. Libbus MK, Bullock LF: Breastfeeding and employment: an assessment of employer attitudes. Journal of Human Lactation 2002, I 8(3):247-25I.

21. Brown CA, Poag S, Kasprzycki C: Exploring large employers' and small employers' knowledge, attitudes, and practices on breastfeeding support in the workplace.[see comment]. Journal of Human Lactation 200I, I7(1):39-46.

22. Losch M, Dungy CI, Russell D, Dusdieker LB: Impact of attitudes on maternal decisions regarding infant feeding. Journal of Pediatrics 1995, I 26(4):507-5 I4.

23. Kloeblen-Tarver AS, Thompson NJ, Miner KR: Intent to breastfeed: the impact of attitudes, norms, parity, and experience. American Journal of Health Behavior 2002, 26(3): 182-187.

24. Galtry J: Extending the'bright line':Feminism,breastfeed and the workplace in the United States. Gender \& Society 2000, 14:295-317.

25. Gartner LM, Morton J, Lawrence RA, Naylor AJ, O'Hare D, Schanler RJ, Eidelman Al: Breastfeeding and the use of human milk. Pediatrics 2005, II 5(2):496-506.

\section{Pre-publication history}

The pre-publication history for this paper can be accessed here:

http://www.biomedcentral.com/1471-2458/6/160/pre $\underline{\text { pub }}$

\section{Publish with Biomed Central and every} scientist can read your work free of charge

"BioMed Central will be the most significant development for disseminating the results of biomedical research in our lifetime. "

Sir Paul Nurse, Cancer Research UK

Your research papers will be:

- available free of charge to the entire biomedical community

- peer reviewed and published immediately upon acceptance

- cited in PubMed and archived on PubMed Central

- yours - you keep the copyright

Submit your manuscript here:

http://www.biomedcentral.com/info/publishing_adv.asp
BioMedcentral 